\title{
Psychological Impact of Nocturnal Enuresis on Self-esteem of School Children
}

\author{
Hanan T. Elbahnasawy ${ }^{1, *}$, Mona A. Elnagar ${ }^{2, *}$ \\ ${ }^{1}$ Pediatric Nursing, El-Menoufy University, Egypt, Currently in Jazan University, KSA \\ ${ }^{2}$ Psychiatric Nursing, El-Menoufy University, Egypt \\ *Corresponding author: hanantharwat2005@yahoo.com, alnagarm@ymail.com
}

Received January 23, 2015; Revised February 27, 2015; Accepted March 10, 2015

\begin{abstract}
Bedwetting is the cause of significant psychosocial stress especially in older children. Aim: The study aimed to assess the psychological impact of nocturnal enuresis on self-esteem of school children. Design: Descriptive research design was used in this study. Setting: The study was conducted in El-Menoufya University Hospital, in Egypt, which consisted of 18 outpatient clinics. The pediatric outpatient clinic of Shebin El-Kom, ElMenoufia University Hospital it is general pediatric outpatient clinic for all children disorders not just for enuresis. Sample: This is a convenient sample of 140 of children representing almost half of the total attendants with nocturnal enuresis during three months duration. The total number of the sample was 70 children of nocturnal enuresis. Tools: For data collection, an interview questionnaire was used to assess socio demographic data, children knowledge about enuresis, psychological impact of enuresis on the children regarding depression and social isolation, self-esteem inventory scale for the children. Finding: The results of the study showed there were no significant difference between gender and their positive self-esteem. In addition, there were no significant difference between psychological problems of the studied children and their positive self-esteem. Conclusion: This study concluded that children in this age have poor knowledge in relation to enuresis. In addition, most of studied children had law selfesteem. Recommendations: According to this study it is recommended that raise community awareness about nocturnal enuresis through educating adolescents in school and universities about nocturnal enuresis, development of health educational program for mothers of enuretic children. Also pediatric nurse, psychiatric nurse, community health nurse and school health nurse offer counseling services for the mothers and their children regarding nocturnal enuresis.
\end{abstract}

\section{Keywords: nocturnal enuresis, psychological impact, children, self-esteem}

Cite This Article: Hanan T. Elbahnasawy, and Mona A. Elnagar, "Psychological Impact of Nocturnal Enuresis on Self-esteem of School Children." American Journal of Nursing Research, vol. 3, no. 1 (2015): 14-20. doi: 10.12691/ajnr-3-1-4.

\section{Introduction}

The total number of school age children in Egypt in the year 2007/2008is about 609742 children in different stages of education [1].

Enuresis is the medical term for bed-wetting during sleep. The word enuresis is derived from a Greek word meaning to make water, also the word "enourein", meaning to void urine [2].

Enuresis is the involuntary or intentional discharge of urine after the age of bladder control, which ranges from 3-7 years of age. However, enuresis should not be diagnosed in a child under the age of 5 years or with a mental age under 4 years. Childhood enuresis whether functional/ psychogenic or organic has been classified into primary and secondary types. Primary enuresis may have been present from birth, which might be an abnormal extension of the normal infantile incontinence. On the other hand, secondary enuresis may have arisen following a period of acquired bladder control. The length of period of continence for making the diagnosis of secondary enuresis ranges between a minimum of two months to a maximum of one year or more [3].

According to the International Children's Continence Society, enuresis or nocturnal enuresis is wetting episodes that occur in discrete amounts during sleep. On the other hand, daytime incontinence or diurnal enuresis is unintended voiding of urine that occurs during the day or wake portion of twenty-four hours" Enuresis is commoner in childhood than daytime incontinence with about $80 \%$ of children with enuresis wetting only at night [4].

Enuresis that persists beyond the age of eight to 10 years may be associated with a poor self-concept or other psychological problems. Reassurance, support, and avoidance of punishment and humiliation are important to maintain the child's self-esteem and minimize parental frustrations [5].

The most difficult aspect of nocturnal enuresis is its effect on a child's self-esteem. Bedwetting can be a source of embarrassment for children causing them to refrain from certain age-appropriate activities such as sleepovers. Parents may become frustrated with their child's wetting 
because it is a drain of time, energy, and money. Some parents punish their children in response to their bedwetting. Although children may develop secondary enuresis after an episode of emotional stress, psychological problems do not cause primary nocturnal enuresis. Examples of stressful situations that can trigger bedwetting include moving to a new home, changing schools, the death of a loved one, or being sexually abused. The wetting usually resolves when the stress passes [6].

Nocturnal enuresis can take a toll on child s self-esteem and is a frustrating problem to parents. The parents are typically the one responsible for the clean up after an accident and are typically charged with finding a cure for the problem. [7] Problem can be stressful for the parents and other family members. Feelings of the parents may range from being worried to frustrated, sad to angry, and even tired. Children may be able to sense these feelings in parents. Children may feel responsible for their parent's reactions and for upsetting the household. It is important to take the positive steps together as a team (parent and child) in getting through the problem of enuresis. Together parents and children should work on ways to diminish feelings of failure and look for ways to encourage good feelings [8]

Psychosocial support is an essential part of care since stress is a significant cause of secondary enuresis. It is important for the child to understand that he or she is not alone. The child should be included in the treatment plan; this help to increase the child's motivation to become dry and Discuss potential strategies with the family to reduce stressors on the child or to help the child cope with the stressors [9].

\section{Aim of the Study}

To assess the Psychological impact of nocturnal enuresis on self-esteem of school children.

\section{Research Questions}

The following research questions guided the present study:

1. What is the level of children knowledge regarding nocturnal enuresis?

2. Is the relationship between the children gender and their self-esteem?

3. Is the relationship between psychological problems of the children and their positive self-esteem?

\section{Subject and Methods}

\subsection{Research Design}

Descriptive research design was used in this study.

\subsection{Setting}

The data was collected from ElMenoufia University Hospital, which consisted of 18 outpatient clinics. The Pediatric outpatient clinic of Shebin El-Kom, ElMenoufia university Hospital it is general pediatric outpatient clinic for all children disorders not just for enuresis.

\subsection{Sample}

The studied subjects represented a convenient sample of 140 of children representing almost half of the total attendants with nocturnal enuresis during three months duration. The total number of the sample was 70 children of nocturnal enuresis.

The sample was selected according to the following criteria:

- Age of children was eight to fourteen years.

- Children had nocturnal enuresis.

- Children had no history of organic diseases.

\subsection{Tools of Data Collection}

An interviewing questionnaire developed by the researchers to collect data, it included the following

\section{A- Socio-demographic data sheet:-}

- Includes socio-demographic data of children such as age, gender, birth order, school achievement, drinking habits and family history of nocturnal enuresis.

\section{B -Children knowledge questionnaire:-}

-The questionnaire was determine children level of information about nocturnal enuresis (definition, types, etiology), (five items), effect and consequence of nocturnal enuresis on the child and family (2 items).

-The responses of the children were scored from one to three scores to assess level of general knowledge. One score for wrong answer, two scores for incomplete answer and three scores for right answer.

-The total scores for general knowledge of children about nocturnal enuresis and other items was determined by stratifying level of general knowledge of children into three categories: poor knowledge from 11- 16 scores, fair knowledge from 17- 25 scores and good knowledge from 26-33 scores.

C-Self concept questionnaire, it was used to assess the psychological impact of nocturnal enuresis on the children regarding to depression and social isolation, adopted from Blleck and Edlun (1992) [10], it is composed of twelve statements, 1) I am happy; 2) I am intelligent; 3) I do not like my appearance; 4) I have good morals in the class; 5) I have good ideas; 6) I am sad; 7) I am shy; 8) I do friendship hardly; 9) I am sometimes worried and nervous; 10) I do had things; 11) I am the most important person in the family; and 12) I solve my problem easily. Answer by "yes" to statements 3, 6, 7, 9, 10 are considered negative self-concept.

\section{D- Self- Esteem Inventory Scale for the children:}

-This tool was developed by [11] and adopted from [12], It was revised by two professors of psychiatry to measure self-esteem of children between the ages of six to fifteen years through attitudes toward the self in social, academic, family and personal areas of experience. The modified scale, which contains 40 items, was divided into two subscales.

\section{a- Positive Self Esteem:-}

It contains 20 statements to measure positive reactions of the children toward illness. One point was given for each item answered "like me" and zero for item "unlike me ". Less than or equal to 10 scores mean low positive self-esteem and more than 10 scores mean high positive self-esteem.

b - Negative Self Esteem 
It contains 20 statements to measure negative reactions of the children toward illness. One point was given for each item answered "like me" and zero for item "unlike me ". Less than or equal to 10 scores mean low negative self-esteem and more than 10 scores mean high negative self-esteem.

\subsection{Validity Test}

Validity test was done by three expertise's of faculties' staff nursing from the pediatric and psychiatric specialists to test the content validity of the study tools (Sociodemographic and knowledge tool).

\subsection{Reliability Test}

Reliability test was done by applying the questionnaire to 10 students using test-retest and Pearson Coefficient factor was $90.8 \%$. The scale was applied on them and retested after 2 weeks. The degree of Spearman's rank correlation coefficient test was (0.82).

\subsection{Operational Design}

\subsubsection{Ethical Considerations}

Personal communication was done with children to explain the purpose of the study and assure their best possible cooperation. The researcher emphasized to children that the study was voluntary and anonymous. Children had the full right to refuse to participate in the study or to withdraw at any time without giving any reason.

\subsubsection{Pilot Study}

A pilot study was carried out on 10 children from the pediatric outpatients in El- Menoufya University Hospitals. It was conducted to test clarity and simplicity of questions and to check the most common topics related to the study. Necessary modifications were done. Children who shared in pilot study were excluded from main study sample.

\subsubsection{Fieldwork}

- Preparation of data collection tools carried out over a period of three months from September 2014 to November 2014 after including experts' opinions, validity, and reliability test.

- Official permissions were obtained from the dean of the faculty, also from administrators of the hospitals.

- A pilot study was carried out to test clarity and simplicity of questions.

- Data collection was carried out over a period three months', three days/week (Monday, Tuesday \& Wednesday). Assessment ranged from 3 to 5 children /day.

- Data Collection were the end of the day in the waiting area in the outpatient clinic after children being examined by physician. The data were covered 12 weeks for collection.

\subsection{Statistical Design}

Data were verified prior to computerized entry. The Statistical Package for Social Science (SPSS), version 18.0 was used for that purpose, followed by data analysis and tabulation. Descriptive statistics were applied (e.g., mean, standard deviation, frequency and percentage). Tests of significance were applied to test the study questions (i.e., paired t-test and Chi-square test). A significant level value was considered when $\mathrm{p}<0.05$.

\section{Results}

Table 1 indicated that the majority of the studied children were at age group from 8-10 years old $78.6 \%$ and $54.3 \%$ were male, while, $52.9 \%$ were first and second birth order. In addition, it was found that $31.4 \%$ were succeeded with satisfactory grades, and $54.3 \%$ had positive family history of nocturnal enuresis.

Table 1. Socio-Demographic data of the studied children No = (70)

\begin{tabular}{|l|l|l|}
\hline Socio-demographic data & No & \% \\
\hline 1-Age (yr.) & & \\
$8<10$ & 55 & 78.6 \\
$10-12$ & 15 & 21.4 \\
\hline 2-Gender & & \\
Male & 38 & 54.3 \\
Female & 32 & 45.7 \\
\hline 3-Birth order $^{\text {stt }}$ nd & & \\
-3rd-5 $^{\text {th }}$ & 33 & 52.9 \\
\hline 4-Scholastic achievement & 37 & 47.1 \\
-Succeed with excellence & & \\
- Succeed with good & 10 & 14.3 \\
- Succeed with satisfactory & 18 & 25.7 \\
- Succeed with subjects & 22 & 31.4 \\
\hline 5- Family history of nocturnal enuresis & 20 & 28.6 \\
\hline - Positive & 38 & 54.3 \\
- Negative & 32 & 45.7 \\
\hline \multicolumn{2}{|l}{} \\
\hline
\end{tabular}

Table 2. Frequency distribution of drinking habits among children No $=$ (70)

\begin{tabular}{|l|l|l|}
\hline Drinking habits & No & \% \\
\hline - Fluid intake in the morning & & \\
$\quad$ - Less than one liter & 46 & 65.7 \\
$\quad$ - More than one liter & 24 & 34.3 \\
\hline - Time of last drink before sleep & & \\
- Just before bed time & 56 & 80 \\
- Before bed time at least two hour & 14 & 20 \\
\hline
\end{tabular}

As shown in the Table 2 the studied children were $65.7 \%$ had fluid intake in the morning less than one liter and $80 \%$ took their last drink just before bedtime.

Table 3. Mean and SD of the studied children knowledge regarding to definition, causes, signs and symptoms of enuresis

\begin{tabular}{|l|c|}
\hline Children Knowledge & Mean and SD \\
\hline Definition of enuresis & $0.92 \pm 1.453$ \\
\hline Causes & \\
\hline -Physical causes & $1.83 \pm 1.281$ \\
\hline -Social causes & $2.62 \pm 0.612$ \\
\hline -Psychological causes & $3.71 \pm 1.241$ \\
\hline -Emotional causes & $2.69 \pm 0.720$ \\
\hline Signs and symptoms of enuresis & $0.98 \pm 0.231$ \\
\hline Enuresis Problems & \\
\hline -Social problems & $2.71 \pm 0.551$ \\
\hline - Psychological problems & $3.81 \pm 1.230$ \\
\hline -Economic problems & $2.48 \pm .521$ \\
\hline Total mean score of Children Knowledge & $24.9 \pm 5.43$ \\
\hline
\end{tabular}


Table 3 Showed that the score of different items of

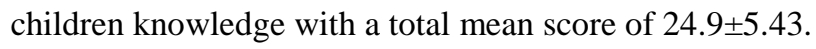

Table 4. Frequency distribution of children knowledge. This table is the answer of research question No (1)

\begin{tabular}{|l|c|c|}
\hline children knowledge & No =(70) & \% \\
\hline Poor knowledge & 32 & 45.7 \\
Fair knowledge & 28 & 40 \\
Good knowledge & 10 & 14.3 \\
\hline
\end{tabular}

Regarding children level of knowledge, it was found from Table 4 that less than half of them (45.7\%) had poor knowledge, (40\%) had fair knowledge and (14.\%) had good knowledge.

Table 5 displayed the self-concept questionnaire, which revealed that two quarters (68.6\%) feel not happy, more than three fifths of them (62.9\%) feel intelligent, more than one third of them (40\%), don't like their appearance, more than two thirds of them (78.6\%) have good moral in class, an equal percentage of less than three quarters of them (58.6\% \&57.1\%) do not have good ideas and feel sad respectively. The majority of enuretic children (87.1\%) feel shy, more than two thirds of them (64.3\%) do friendships hardly, and most of them (82.9\%) are sometimes worried and nervous. Less than three quarters of them (72.9\%) do bad things, and two thirds of them (61.4\%) feel they are not the most important person in the family and more than two thirds of them (70\%) do not solve their problems easily.

Table 6 revealed that the majority of the studied children (68.6\%) had low positive self-esteem and only (31.4\%) had high positive self-esteem. More than two thirds of the studied children (65.7\%), had low negative self-esteem and only (34.3\%) had high negative selfesteem.

Table 5. Assessment of self-concept condition of enuretic children

\begin{tabular}{|l|c|c|}
\hline \multicolumn{1}{|c|}{ Variables } & Yes \% & No\% \\
\hline I am happy & 31.4 & 68.6 \\
\hline I am intelligent & 62.9 & 37.1 \\
\hline I do not like my appearance & 40 & 60 \\
\hline I have good morals in the class & 78.6 & 21.4 \\
\hline I have good ideas & 41.4 & 58.6 \\
\hline I am sad & 57.1 & 42.9 \\
\hline I am shy & 87.1 & 12.9 \\
\hline I do friendship hardly & 64.3 & 35.7 \\
\hline I am sometimes worried and nervous & 82.9 & 17.1 \\
\hline I do had things & 72.9 & 27.1 \\
\hline I am the most important person in the family & 38.6 & 61.4 \\
\hline I solve my problem easily & 30 & 70 \\
\hline
\end{tabular}

Table 6. Frequency distribution of positive Self-Esteem and Negative Self-Esteem among Children No $=\mathbf{7 0})$

\begin{tabular}{|l|l|l|}
\hline Children self -esteem & No & \% \\
\hline Positive self-esteem & & \\
- Low positive self-esteem & 48 & 68.6 \\
- High positive self-esteem & 22 & 31.4 \\
\hline Negative self -esteem & & \\
- Low negative self-esteem & 46 & 65.7 \\
- High negative self-esteem & 24 & 34.3 \\
\hline
\end{tabular}

Table 7. The relationship between the child's gender and their positive self-esteem. Table $(7 \& 8)$ is the answer of research question No (2)

\begin{tabular}{|c|c|c|c|c|c|c|}
\hline \multirow{3}{*}{$\begin{array}{l}\text { The child's } \\
\text { gender }\end{array}$} & \multicolumn{4}{|c|}{$\begin{array}{c}\text { Positive self-esteem before the } \\
\text { intervention }\end{array}$} & \multirow{3}{*}{$X^{2}$} & \multirow{3}{*}{$\mathbf{p}$} \\
\hline & \multicolumn{2}{|c|}{$\begin{array}{l}\text { Low positive } \\
\text { self esteem }\end{array}$} & \multicolumn{2}{|c|}{$\begin{array}{l}\text { High positive } \\
\text { self esteem }\end{array}$} & & \\
\hline & No & $\%$ & No & $\%$ & & \\
\hline - Male & 26 & 37.2 & 14 & 20 & 1.5 & 0.22 \\
\hline - Female & 22 & 31.4 & 8 & 11.4 & & N.S \\
\hline
\end{tabular}

Regarding the relationship between the child's gender and their positive self-esteem, Table 7 revealed that no statistically significant difference was found between male and female where $\mathrm{P}>0.05$.

Table 8. The relationship between the child's gender and their negative self-esteem

\begin{tabular}{|c|c|c|c|c|c|c|}
\hline \multirow{3}{*}{$\begin{array}{l}\text { The child's } \\
\text { gender }\end{array}$} & \multicolumn{4}{|c|}{$\begin{array}{c}\text { Negative self-esteem before the } \\
\text { intervention }\end{array}$} & \multirow{3}{*}{$X^{2}$} & \multirow{3}{*}{$\mathbf{p}$} \\
\hline & \multicolumn{2}{|c|}{$\begin{array}{c}\text { Low negative } \\
\text { self esteem }\end{array}$} & \multicolumn{2}{|c|}{$\begin{array}{l}\text { Highnegative } \\
\text { self esteem }\end{array}$} & & \\
\hline & No & $\%$ & No & $\%$ & & \\
\hline - Male & 25 & 35.7 & 15 & 21.4 & 1.06 & 0.30 \\
\hline - Female & 21 & 30 & 9 & 12.9 & & N.S \\
\hline
\end{tabular}

Regarding the relationship between the child's gender and their negative self-esteem, the data from Table 8 revealed that no statistically significant difference was found, where $\mathrm{P}>0.05$.

Table 9. The relationship between psychological problems of the studied children and their positive self-esteem. This table is the answer of research question No (3)

\begin{tabular}{|l|l|l|l|l|l|l|}
\multirow{2}{*}{$\begin{array}{l}\text { Psychological } \\
\text { problems of the } \\
\text { children }\end{array}$} & \multicolumn{2}{|l|}{ The child's positive self esteem } & \multirow{2}{*}{$\begin{array}{l}\text { Low positive self } \\
\text { esteem }\end{array}$} & \multicolumn{2}{|l|}{$\begin{array}{l}\text { High positive } \\
\text { self esteem }\end{array}$} & \multirow{2}{*}{ p } \\
\cline { 2 - 5 } & No & $\%$ & No & $\%$ & & \\
\hline - Social isolation & 13 & 18.5 & 3 & 4.3 & 1.9 & $\mathbf{0 . 7 3}$ \\
- Aggression & 3 & 4.3 & 2 & 2.9 & & N.S \\
- Hyperactivity & 2 & 2.9 & 4 & 5.7 & & \\
$\begin{array}{l}\text { - Embarrassment } \\
\text { - Aggression \& } \\
\text { hyperactivity }\end{array}$ & 20 & 28.6 & 12 & 17.1 & & \\
\hline
\end{tabular}

The Table 9 illustrates that there were no statistically significant difference between psychological problems of the studied children and their positive self-esteem where $\mathrm{P}>0.05$.

\section{Discussion}

Many children with a bed-wetting problem suffer from low self-esteem, shame, and guilt. They have feelings of failure and see themselves as different from other people. Children with a bedwetting problem are afraid of being discovered and often fear being teased and humiliated by their peers. These feelings are heightened if the individual also suffers from daytime "accidents" which can accompany nocturnal enuresis [7].

Regarding to socio-demographic characteristics of the enuretic children, this study result showed that the age of enuretic children for more than half of them, ranged between $8<10$ years and were male (Table 1 ). This finding may be due to the incidence of enuresis decrease gradually with increasing age. This finding similar to that of another study conducted at the Outpatient Clinic of Psychiatric 
Hospital's in Tanta University Hospital where enuresis was reported to be higher in children aged 9 to $<12$ years old compared to those in the age category of $6-<9$ years [13] also, Butler \& Heron reported that nocturnal enuresis is a prevalent and potentially distressing experience for children and their parents. Around 15-22\% of boys and 7$15 \%$ of girls wet the bed at 7 years of age, with almost $3 \%$ wetting more than twice a week, Combined (day and night) wetting has been reported in 3.3\% of 7 -year-olds and $4 \%$ of children aged 5-12 years [14] Also Wolfish, added that among children older than seven years the condition is twice as common in boys as girls. Also this finding revealed that the enuretic children were males This finding may be attributed to the culture of mothers of enuretic children residing rural areas who are over interested in boys more than girls, accompanying boy to seek medical treatment for them [15]. The present study also agreed with Aljenaie, who found that nocturnal enuresis is more common in boys (13.7\%) than in girls (11.3\%) [16]. Additionally, this study finding is congruent with the finding of Wenetal., who found that nocturnal enuresis is more common and prolonged in boys than in girls, however they attributed it difference in anatomical structure of urinary system between males and females [17].

Concerning birth order i.e., the rank of enuretic child in the family, the present study found that enuresis was prevalent among the first and second born children in the family accounting for more than fifty of the studied sample (Table 1). This finding may be due to an inadequate experience and knowledge of mother about correct toileting and lack of awareness how to deal with their children. This finding agreed with Ahmed, who found an increased frequency of first child order enuretics with a percentage of $53 \%$ of the studied cases within small sized families. This may be because first-born children could be more attached to their mothers in addition to the lack of mothers' experience and awareness about the psychological factors related to occurrence of enuresis and how to deal with their children [18]. As regards scholastic achievement, the result of present study revealed that one third of enuretic children succeeded with satisfactory grades. This finding is in agreement with Ahmed, who found that majority of enuretic children have acceptable achievement and less than one quarter had good achievement [18], these findings were opposite to that of Saforinjad, whose studied children results were associated with poor school performance and poor relationships with classmates [19].

Considering family history of enuresis in the same table the study revealed that more than fifty of children were had positive family history of enuresis. These finding may be attributed to the presence of genetic factor in occurrence of nocturnal enuresis which agreed with Joinsn., et al who reported that family history of nocturnal enuresis is found in most enuretic children. The incidence of primary nocturnal enuresis is important to take the positive steps together as a team $77 \%$ among children who have both a parents with a history of primary nocturnal enuresis. This rate decreased to $43 \%$ in children who have just one parent with a primary nocturnal enuresis and to $15 \%$ in children who have no parental history of primary nocturnal enuresis [20]. In addition, Ismail, added that positive family history was detected in $74 \%$ of all children, in $65 \%$ in children with primary nocturnal enuresis, $93 \%$ in children with secondary nocturnal enuresis [21].

Regarding the drinking habits of the enuretic children (Table 2) the present study showed that two third of the studied children were had fluid intake in the morning less than one liter and majority took their last drink just before bedtime. This result in agreement with El-Nagar, who reported that more than half of the enuretic children took their last drink just before bedtime. This may be due to the presence of the children in schools for at least six hours without drinking or with minimal drinking to avoid going to the bathroom in the school and may be related to eating large amount of food rich in salt in lunch that make the child drink more in the night [22]. Also, this result agree with Elsaid, who reported that the majority of children fluid intake in the morning was less than one liter and took their last drink just before bedtime [23].

Regarding to children total mean score of knowledge

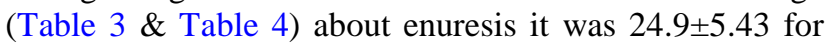
different items, which revealed that children in this age have poor knowledge score in relation to enuresis. This finding might be duo to that the children have not information or knowledge about enuresis because their mothers have not information or may consider that children punished only for enuresis but not understanding him anything.

As regards self-concept of enutetic children, the present study revealed that slightly more than three quarters of enuretic children have low self-concept and less than one quarter of them had high self-concept (Table 5). As clarified by Warzak, nocturnal enuresis perceived as a shameful condition and giving a significant impairment of self-esteem of enuretic children at an age when an intact self-image is extremely important for an optimal development of child personality [24].

The present study revealed that the two thirds of the studied children had low self-esteem (Table 6). Consistent with the present study Joinsn., et al mentioned that bedwetting children did not reduced self-esteem compared with those with no bedwetting problem and reporting no evidence to suggest that children with bedwetting construe themselves more negatively than children with no wetting problem [20]. Moreover Van Hoeck, et al and another reported no difference in self-esteem level between children with and children with no wetting problem [25]. This result explained by Chang and Wong, who mentioned that nocturnal enuresis is a health problem that can have adverse consequences and can result in poor selfesteem for the child as well as frustration and anger for the parents. Children with a bedwetting problem often suffer from shame and guilt, and may have feelings of failure and view themselves as different from others. Children with a bedwetting problem are afraid of being discovered by their peers, and often fear teasing and humiliation by their own siblings and relatives. Nocturnal enuresis is profoundly affects the child's life socially, emotionally, and behaviorally and also impacts the everyday life of his/her family [26]. Regarding the child's gender and their self-esteem the present study showed that the male children had low self esteem more than female children with no statistically significant difference (Table 7 \& Table 8). This result consistent with Butler, and Swithinbank, who mentioned that boys were significantly more likely to view bed wetting as more difficult problem for children 
than girls did [27]. And Landgraf, et al who suggesting that the effects of enuresis as perceived by parents may be more negative for boys than girls [28]. Contradicting to the above results Theunis, reported that enuretic girls had a significantly lower perceived competence than enuretic boys did. This may be due to the male children always aggressive and hyperactive that may trigger their mother to use physical abuse to control their behavior that may lower the self -esteem more than female children [29]. Concerning psychological problems of children, there were no statistically significant difference between psychological problems of the studied children and their positive self-esteem (Table 9) because enuresis carries such a stigma in our society, the emotional impact of nocturnal enuresis on a child and family can be enormous.

This finding was in accordance with Robson, who found that children with nocturnal enuresis are commonly punished and are at significant risk of emotional and physical abuse which lead to feelings of embarrassment and anxiety in children with enuresis; loss of self-esteem; and effects on self-perception, interpersonal relationships, quality of life, and school performance [30]. The present study was revealed that about half of the enuretic children were embarrassed and followed by social isolation. Additionally other studies agree with the result of the present study Joinson, et al who found evidence for increased levels of psychological problems in children who wet the bed compared with those who do not wet the bed with more internalizing and externalizing problems [20]. Also, McKillop, et al reported that during discussions around the enuretic children experience of wetting the bed, the children's body language was more reserved and closed there was, for example, no eye contact and at times they were excessively fidgety, the following words were used to describe their feelings: embarrassing, unsafe, shy and scared. some of the negative experiences the children had to endure included being laughed at and teased [31]. Moreover Ozkan, et al reported that the impact of bed wetting as an adverse life event was comparable to poor academic attainment and experience of being teased frequently, feel ashamed, sad and feel embarrassed [32]. Whoever Robinson, et al mentioned no increased rates of psychological problems in children who wet the bed [33]. In another study the association between bedwetting and psychological problems disappeared after adjusting for socioeconomic status by Van Hoecke, et al this may be due to feelings of the child that he is different than other sibling and also may be due to teasing of siblings or parents. Also psychological problems could be related to inability of the mothers to adjust or manage their problems; when the mothers are able to cope with their feelings they will be able to reassure their children [25].

Older children have more psychological consequences of the wetting problem. The perceived competence decreases in children with nocturnal enuresis as the age increases, while the perceived competence increases in children without nocturnal enuresis as the age increases. Our results are in accordance with few previous studies such Fergusson and Horwood suggest a small but detectable increase in behavior problems with children with wetting problems after the age of 10 years. Such children may react to problems with nocturnal bladder control by becoming more disruptive, inattentive, or difficult to manage. Bed-wetting after the age of 10 years is associated with small but detectable increases in risk of conduct problems, attention deficit behaviors and anxiety/withdrawal in early adolescence [34].

\section{Conclusion}

This study concluded that the age of enuretic children for more than half of them, ranged between $8<10$ years and were male, two third of them were had fluid intake in the morning less than one liter and majority took their last drink just before bedtime, children in this age have poor knowledge in relation to enuresis, slightly more than three quarters of enuretic children have low self-concept and less than one quarter of them had high self-concept and two thirds of them had low self-esteem. The child's gender and their self-esteem the present study showed that the male children had low self-esteem more than female children with no statistically significant difference, there were no statistically significant difference between psychological problems of the studied children and their positive self-esteem.

\section{Recommendations}

Based on the findings of the present study, it could be recommended that:

- Raise community awareness about nocturnal enuresis and decrease the incidence of bedwetting through:

-Educating adolescents in schools and universities about nocturnal enuresis because they will be the parent of the future.

- Development of a health educational program for mothers of enuretic children to update their knowledge and skills about the advancing technology in the health care of their enuretic children. This educational program could be delivered through mass media, posters, booklets, $\mathrm{MCH}$ centers and individual counseling.

- Pediatric nurse, Psychiatric nurse, Community health nurse and school health nurse should offer counseling services for the mothers and their children regarding nocturnal enuresis. It should be aimed at relieving their misconceptions, worries, guilt and psychological impacts resulting from improper management of nocturnal enuresis.

\section{References}

[1] World Health Organization, Promoting Health through Schools. Rep.Ser, No 870, 2007.

[2] Najeeb M., Effect of the Educational Program upon Parents' Knowledge of Nocturnal Enuretic Children, World Journal of Medical Sciences 7 (3): 137-146, 2012.

[3] Al-Ghamdy, Y., Qureshi, N.,, and Abdelgadir, M., Childhood enuresis Epidemiology, pathophysiology and management, Saudi Medical Journal 2000; Vol. 21 (2): 138-144.

[4] Nevéus T, von Gontard A, Hoebeke P, Hjälmås K, Bauer S, Bower W, Jørgensen TM, Rittig S, Walle JV, Yeung C, Djurhuus JC. The standardization of terminology of lower urinary tract function in children and adolescents: Report from the standardisation committee of the International Children's Continence. Society J Urol. 2006;176: 314-324.

[5] Senbanjo, I., Oshikoya, K., and Njokanma, O., Micturitional dryness and attitude of parents towards enuresis in children attending outpatient unit of a tertiary hospital in Abeokuta, Southwest Nigeria, Afr Health Sci. Jun 2011; 11(2): 244-251. 
[6] Feldman, M., Management of primary nocturnal enuresis, Canadian Paediatric Society, Community Paediatrics Committee, PediatricChild Health 2005;10(10):611-4 Posted: Dec 12005 Updated: Jan 302013 Reaffirmed: Feb 12014.

[7] Caldwell, P., Edgar, D., Hodson, E., and Craig, J. Bedwetting and toileting problems in children, MJA Practice Essentials Paediatrics; (182) (4), 2005, 190-195.

[8] Goin, R. P.: Nocturnal enuresis in children, childcare, Health and Development, Vol. 34(4), 1998, pp. 277-288.

[9] Ricci, S, and, Kyle, T. Nursing care of the child with agenitourinary disorder. In Maternity and pediatric nursing, 2009.

[10] Blleck, J. and Edlund, P.Nursing Assessment and diagnosis. London: Jones and Bartlet, 1992, p115.

[11] Coopersmith. Self- Esteem Inventory Scale for the children, 1967.

[12] Youssef, Modified Self- Esteem Inventory Scale for the children, 1988.

[13] Ahmed, A.A. Assessment of mothers knowledge, attitude and practice regarding their enuretic children, $\mathrm{PhD}$ Thesis in community, Ain Shams University, 2002.

[14] Butler, R., and Heron, J. The prevalence of infrequent bedwetting and nocturnal enuresis in childhood: A large British cohort Scandinavian Journal of Urology and Nephrology; 42 (3), 2008; 257-64.

[15] Wolfish, N. Management of nocturnal enuresis in children. Clinical Review; 142(2), 2009: 76-80.

[16] Aljenaei, A. Prevalence of Nocturnal Enuresis among Qatari Students aged 6 to 12 years, 2009, Doha, Qatar 7-8

[17] Wen, J.G., Wang, W., Chen, y., Wen, J.J., and Liu, K.An Epidemiological Study of Primary Nocturnal Enuresis in Chinese Children and Adolescents. EurUrol:(49), 2006, 1107: 13.

[18] Ahmed, M.M. Mothers Care for their children regarding enuresis in Rural Areas, PhD Thesis in community, Benha University, 2010.

[19] Safarinejad, M. Prevalence of nocturnal enuresis, risk factors, associated familial factors and urinary pathology among school children in Iran. Pediatric Urology; 2007, 3:443-452.

[20] Joinson, C., Heron, J., Emond, A., and Butler, R. Psychological problems in children with bed-wetting and combined (day and night) wetting. Journal of Paediatric Psychology; 32(5), 2007, 605-16.

[21] Ismail, S.A. Ultrasonographic evaluation in children with nocturnal enuresis. PhDThesis of pediatrics, Faculty of Medicine, Ain Shams University, 2007.
[22] El-Nagar,S. Identification of needs as perceived by school age children and their mothers and it's effect on their adjustment with enuresis.(Thesis) Faculty of Nursing, Menoufia University, 2003.

[23] Elsaid, S.M.Impact of Educational Programme on Self Esteem of Children with Nocturnal Enuresis and Their Mother's Anxiety and Depression, PhD Thesis in Psychiatric Nursing, El Menoufya University, 2013.

[24] Warzak, W.J. Pschosocial Implications of Nocturnal Enuresis, Clinical Pediatrics, Sepc 32(1), 2006, 38: 40.

[25] Van Hoecke E, Hoebeke P, Braet C, Walle JV. An assessment of internalizing problems in children with enuresis. J Urol;171( 2), 2004, 2580-2583.

[26] Chang, S., Ng, S and Wong, S. Behavioral problems in children and parenting stress associated with primary nocturnal enuresis in Hong Kong. ActaPaediatr.; 2002, 91:475-479.

[27] Butler R.,\&Swithinbank L. Nocturnal Enuresis and Daytime Wetting: A Handbook for Professionals. Bristol: Education and Resources for Improving Childhood Continence, 2007.

[28] Landgraf, J., Abidari, J., Cilento, B., Cooper, C., Schulman, S\&Ortenberg,J. Coping, commitment, and attitude: quantifying the everyday burden of enuresis on children and their families. Pediatrics; 2004, 113:334 -344.

[29] Theunis, M., Van Hoecke, E., Paesbrugge, S., Hoebeke, P., VandeWalle, J. Self-image and performance in children with nocturnal enuresis. EurUrol; 2002, 41:660-667

[30] Robson, L. Current management of nocturnal enuresis. Wolters Kluwer Health, Lippincott Williams \& Wilkins; 2011, 18:425-430

[31] McKillop A., Mackay B.,andScobie N. A programme for children with nocturnal enuresis, Nurse Stand; 17(43), 2003, 33-8.

[32] Ozkan, K., Garipardic, M., Toktamis, A., Karabiber, H., Sahinkanat, T. Enuresis prevalence and accompanying factors in school children: a questionnaire study from southeast Anatolia. UrolInt ; 2004, 73:149-55.

[33] Robinson,J., Butler,R., Holland, P \& Doherty-Williams, D.(2003). Self-Construing in children with primary mono-symptomatic nocturnal enuresis: An investigation of three measures. Scandinavian Journal of Urology and Nephrology; 37: 2003, 124128.

[34] Fergusson, J. and Horwood, L. Nocturnal enuresis and behavioural problems in adoscence: A 15-year longitudinal study. Paediatrics. 1994;94(5):662-668. 